Oral presentation

\title{
Myocardial scar in pulmonary hypertension: relationship to pulmonary hemodynamics, right ventricular function and remodeling
}

\author{
Monda L Shehata*1, Jan Skrok ${ }^{1}$, Dirk Lossnitzer ${ }^{2}$, Stephen C Mathai ${ }^{1}$, \\ Danielle Boyce ${ }^{1}$, Noah Lechtzin ${ }^{1}$, Nael Osman ${ }^{1}$, Joao AC Lima1, \\ David A Bluemke ${ }^{3}$, Paul Hassoun ${ }^{1}$ and Jens Vogel-Claussen ${ }^{1}$
}

Address: ${ }^{1}$ Johns Hopkins University, Baltimore, MD, USA, ${ }^{2}$ University of Heidelberg, Heidelberg, Germany and ${ }^{3}$ National Institutes of Health (NIH), Bethesda, MD, USA

* Corresponding author

from I3th Annual SCMR Scientific Sessions

Phoenix, AZ, USA. 21-24 January 2010

Published: 21 January 2010

Journal of Cardiovascular Magnetic Resonance 2010, I2(SuppI I):O5I doi:I0.II86/I532-429X-I2-SI-O5 I

This abstract is available from: http://jcmr-online.com/content/I2/SI/O5I

(C) 2010 Shehata et al; licensee BioMed Central Ltd.

\section{Introduction}

Right ventricular (RV) functional and structural monitoring is important as a prognostic measure in pulmonary hypertension $(\mathrm{PH})$ patients. Cardiac magnetic resonance (CMR) imaging is the standard of reference for RV anatomical and functional assessment. Using delayed enhancement (DE)-CMR, presence of myocardial scar in association with PH was typically described at the RV septal insertions. However, its etiology in relation to RV remodeling, altered regional mechanics and pulmonary hemodynamics has not been fully assessed.

\section{Purpose}

To identify predictors of scar burden at the RV septal insertions in PH patients.

\section{Methods}

We prospectively evaluated 38 patients with suspected $\mathrm{PH}$ with right heart catheterization (RHC) and CMR. 10 agematched controls were included for CMR study comparison. Septal DE mass was quantified at the RV insertions. Systolic septal eccentricity index (EI), global RV function and remodeling indices were quantified using cine short axis images. Regional peak systolic circumferential $\left(\mathrm{E}_{\mathrm{CC}}\right)$ and longitudinal $\left(\mathrm{E}_{\mathrm{LL}}\right)$ strain were measured at the DE- corresponding sites using conventional tagged and Fast strain encoding acquisitions respectively.

\section{Results}

$\mathrm{PH}$ was diagnosed in 32 patients. DE was noted in $31 / 32$ $\mathrm{PH}$ patients and $1 / 6$ suspected but absent $\mathrm{PH}$ patients (mean DE mass $\pm \mathrm{SD}=4.6 \mathrm{~g} \pm 3.3$ and $0.6 \mathrm{~g} \pm 1.5$ for both

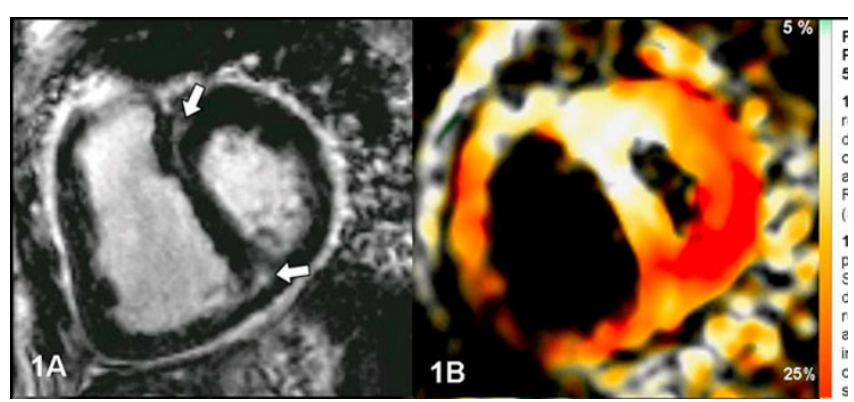

Figure I

72 yr olf PH patient (mPAP = $53 \mathbf{~ m m H g})$. IA) GRE inversion recovery image deomonstrating areas of LV DE at the basal anterior and posterior RV septal insertions (arrows). IB) Corresponding peak systolic Fast-SENC image demonstrating reduced $\mathrm{E}_{\mathrm{LL}}$ at the anterior $\mathrm{RV}$ septal insetion (white) compared to posterior septal insertion (red). 


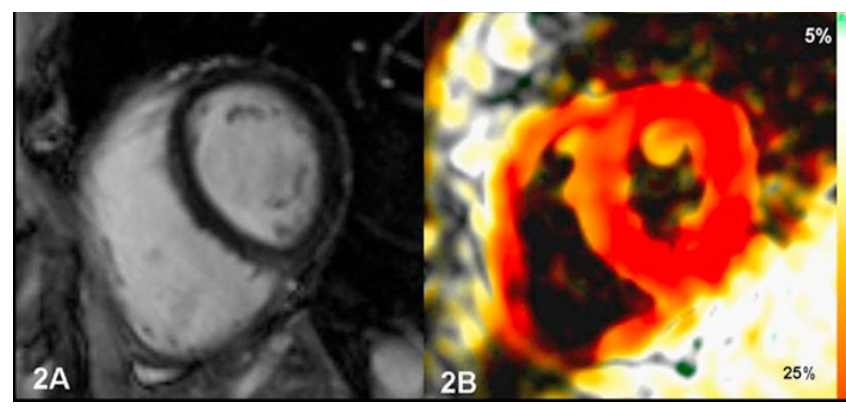

Figure 2

59 yr old non PH patient (mPAP = I $8 \mathrm{mmHg}$ ). 2A) GRE inversion recovery image at the base of LV. 2B) Corresponding peak systlic Fast-SENC image demonstrating normal $E_{\mathrm{LL}}$ at both RV attachment sites.

groups respectively, $\mathrm{p}=0.001)$. No DE was detected in controls. DE was more prevalent at the posterior septal insertion (PSI) compared to the anterior septal insertion (ASI). DE mass correlated with reduced RV function and increased RV remodeling indices. DE mass was associated with reduced $\mathrm{E}_{\mathrm{LL}}$ at the base $(\mathrm{r}=0.6, \mathrm{p}<0.01)$ (Figure 1, $2)$. Similarly, it correlated with reduced EI $(r=-0.4$ for ASIDE, $r=-0.5$ for PSI-DE, $\mathrm{p}<0.05)$. Using multivariate regression including $\mathrm{RV}$ and $\mathrm{LV}$ mass indices, RV ejection fraction, EI and mPAP as parameters, RV mass index was an independent predictor of total DE mass $(\beta=0.65, \mathrm{p}<$ $0.001)$. On regional analysis including: mPAP, RV mass index, $\mathrm{EI}, \mathrm{E}_{\mathrm{LL}}$ and $\mathrm{E}_{\mathrm{CC}}$ as parameters, $\mathrm{E}_{\mathrm{LL}}$ at the base remained an independent predictor of DE mass at the ASI ( $\beta=0.69, p=0.002)$, whereas, elevated mPAP was an independent predictor of DE mass at the PSI $(\beta=0.4, \mathrm{p}=$ 0.03).

\section{Conclusion}

In $\mathrm{PH}$, total scar burden at the RV septal insertions is predicted by measures of $\mathrm{RV}$ remodeling in response to increased RV after-load. Local scar mass at the ASI is associated with reduced regional longitudinal contractility at the base of the left ventricle.
Publish with BioMed Central and every scientist can read your work free of charge

"BioMed Central will be the most significant development for disseminating the results of biomedical research in our lifetime. " Sir Paul Nurse, Cancer Research UK

Your research papers will be:

- available free of charge to the entire biomedical community

- peer reviewed and published immediately upon acceptance

- cited in PubMed and archived on PubMed Central

- yours - you keep the copyright

Submit your manuscript here:

http://www.biomedcentral.com/info/publishing_adv.asp
BioMedcentral 